\title{
Changes in immune functions in bottlenose dolphins in the northern Gulf of Mexico associated with the Deepwater Horizon oil spill
}

\author{
Sylvain De Guise ${ }^{1,2, *}$, Milton Levin ${ }^{1}$, Erika Gebhard ${ }^{1}$, Lindsay Jasperse ${ }^{1}$, \\ Leslie Burdett Hart ${ }^{3,4}$, Cynthia R. Smith ${ }^{5}$, Stephanie Venn-Watson ${ }^{5}$, Forrest Townsend ${ }^{6}$, \\ Randall Wells ${ }^{7}$, Brian Balmer ${ }^{4,7}$, Eric Zolman ${ }^{4}$, Teresa Rowles ${ }^{8}$, Lori Schwacke ${ }^{4}$ \\ ${ }^{1}$ University of Connecticut, Department of Pathobiology and Veterinary Science, Storrs, Connecticut 06269, USA \\ ${ }^{2}$ Connecticut Sea Grant Program, Groton, Connecticut 06340, USA \\ ${ }^{3}$ College of Charleston, Department of Health and Human Performance, Charleston, South Carolina 29424, USA \\ ${ }^{4}$ National Centers for Coastal Ocean Science, National Oceanic and Atmospheric Administration, Charleston, \\ South Carolina 29412, USA \\ ${ }^{5}$ National Marine Mammal Foundation, San Diego, California 92106, USA \\ ${ }^{6}$ Bayside Hospital for Animals, Fort Walton Beach, Florida 32547, USA \\ ${ }^{7}$ Chicago Zoological Society, c/o Mote Marine Laboratory, Sarasota, Florida 34236, USA \\ ${ }^{8}$ Office of Protected Resources, National Marine Fisheries Service, National Oceanic and Atmospheric Administration, \\ Silver Spring, Maryland 20910, USA
}

\begin{abstract}
Following the Deepwater Horizon (DWH) oil spill, the Natural Resource Damage Assessment conducted comprehensive health assessments on common bottlenose dolphins Tursiops truncatus in Barataria Bay (BB), Louisiana, in 2011, 2013 and 2014, as well as in Mississippi Sound (MS) in 2013, to assess potential health effects from exposure to oil compared to Sarasota Bay (SB), Florida dolphins not exposed to DWH oil. Immune functions demonstrated a consistent increase in T (BB 2011) and B (BB 2011 and 2013) lymphocyte proliferation compared to SB. Cytokine concentrations varied considerably in wild dolphin populations, and no significant differences were found; however, interesting trends were observed. The Th1 cytokines IL-2, IL-12, and IFN $\gamma$, and the Th2 cytokines IL-5, IL-10, and IL-13, were 2- to 50-fold lower, and IL-4 was 3-fold higher, in BB 2011 compared to SB. Overall, the changes observed were compatible with those documented in other species following exposure to oil or PAHs and were most pronounced in BB 2011, at the place and time most affected by oil. The changes in T cell functions, and the trend towards a cytokine balance tilted towards a Th2, rather than a Th1 response, are compatible with intra-cellular bacterial infections such as Brucella, which has been identified as one of the potential contributory factors to perinatal dolphin mortalities, and changes in B cell functions are compatible with an increase in extra-cellular bacterial infections and primary bacterial pneumonia.
\end{abstract}

KEY WORDS: Oil spill · Bottlenose dolphin $\cdot$ Lymphocyte proliferation $\cdot$ Cytokines $\cdot$ Immunology Immunotoxicology $\cdot$ Health

\section{INTRODUCTION}

The explosion of the Deepwater Horizon (DWH) oil platform on April 20, 2010 resulted in an unprecedented release of oil in the Gulf of Mexico (GoM).

\footnotetext{
*Corresponding author: sylvain.deguise@uconn.edu
}

Millions of barrels of oil were discharged into the Gulf from the DWH well before it was successfully capped on July 15, 2010 (United States District Court 2014). Common bottlenose dolphins Tursiops truncatus are long-lived apex predators likely to be ex-

(C) The authors and (outside the USA) the US Government 2017. Open Access under Creative Commons by Attribution Licence. Use, distribution and reproduction are unrestricted. Authors and original publication must be credited.

Publisher: Inter-Research · www.int-res.com 
posed to oil or its by-products through respiratory, alimentary, and dermal routes (Schwacke et al. 2014). Dolphins, as well as other cetaceans, may be able to detect the presence of oil but do not necessarily avoid it (Gubbay \& Earll 2000).

Specific health effects reported from live common bottlenose dolphin health assessments from Barataria Bay (BB), Louisiana in 2011, an area that received heavy and prolonged oiling, were compared to a reference site, Sarasota Bay (SB), Florida, where oil was not observed. These health effects in dolphins likely exposed to oil included hypoadrenocorticism, consistent with adrenal toxicity as previously reported for laboratory mammals exposed to oil, and a 5 times increased likelihood of moderate to severe lung disease (Schwacke et al. 2014). Consistent findings of adrenal and lung abnormalities were also identified in dolphins that stranded and died within the DWH oil spill footprint, including BB. Specifically, dolphins that stranded post-DWH oil spill had a higher prevalence of thin adrenal gland cortices, severe pneumonia, and primary bacterial pneumonia compared to a reference population of dolphins that stranded outside of the DWH oil spill footprint and time (Venn-Watson et al. 2015). Combined, these studies supported the conclusion that exposure to petroleum products from the DWH oil spill led to adrenal and lung disease in dolphins and contributed to the observed increase in dolphin mortalities (Venn-Watson et al. 2015). In addition, there were increased numbers of perinatal dolphin strandings during the years following the DHW oil spill (Colegrove et al. 2016). Perinatal studies support the hypothesis that most of these late-term pregnancy losses were likely due to poor maternal health following the DHW oil spill, including increased in utero infections, such as brucellosis (Colegrove et al. 2016).

The immune system normally ensures a balance between maintaining an individual's homeostasis and preparing for a potential pathogen invasion. It includes adaptive and innate branches, each with specific cell types and functions that can be quantified. The in vitro mitogen-induced lymphocyte proliferation assay measures the ability of lymphocytes to proliferate in response to a broad, not antigenspecific stimulation, as a representation of an initial and important first step of the adaptive immune response (De Guise et al. 1996). Cytokines are small cell-signaling protein molecules secreted by numerous cells of the immune system, which determine the direction and magnitude of an immune response. These include interferon, interleukin (IL), and growth factors. Commonly, cytokines are divided into pro- inflammatory and anti-inflammatory groups. Proinflammatory cytokines, secreted in the beginning of an immune response, include IL-1, IL-6, IL-8, and tumor necrosis factor (TNF), and are produced predominantly by macrophages, monocytes, and $\mathrm{T}$ helper 1 (Th1) lymphocytes. Anti-inflammatory cytokines, secreted to dampen an inflammatory response, include IL-4, IL-10, and IL-13 and are secreted predominately by $\mathrm{T}$ helper 2 (Th2) lymphocytes. Cytokines can define the direction of an immune response orchestrated by $\mathrm{T}$ helper cells. Th1 cells secrete interferon gamma (IFN $\gamma$ ), IL-2, and IL-12, which stimulate cell-mediated immunity to help combat intracellular pathogens (e.g. viruses and intra-cellular bacteria). On the other hand, Th2 cells produce IL-4, IL-10, IL-6, and IL-13, which inhibit cell mediated (Th1) immunity and promote humoral (i.e. antibody mediated) immune responses to help combat extracellular pathogens (e.g. extracellular bacteria, parasites) (Kuby 1997).

During and following the DWH oil spill, significantly elevated polycyclic aromatic hydrocarbon (PAH) levels attributed to DWH oil were detected in coastal GoM waters, including Louisiana, Mississippi, and Alabama (Allan et al. 2012). PAHs are an important class of environmental pollutants associated with oil spills and have known immunotoxic effects (Davila et al. 1995, Reynaud \& Deschaux 2006, Zaccaria \& McClure 2013). A recent review concluded that exposure to benzo(a)pyrene (BaP), a model PAH mostly of pyrogenic origin, affects primary and secondary immune tissues as well as peripheral (circulating) immune cells, resulting in altered cellular proliferation, differentiation and survival through mechanisms that are complex and include aryl hydrocarbon receptor (AhR)-dependent pathways (Zaccaria \& McClure 2013). While several studies have investigated the immunotoxicity of individual or groups of PAHs, relatively few have assessed the effects of direct exposure to oil. In a hallmark study, mink Neovison vison with chronic experimental exposure to bunker $\mathrm{C}$ fuel oil had increased $\mathrm{T}$ cell proliferation, increased absolute numbers of specific peripheral blood lymphocyte subsets (CD3+T cells) and monocytes, and increased level of expression of functionally significant cell surface proteins including MHC II and CD18 (Schwartz et al. 2004). Those results are compatible with previously described immune suppression upon exposure to high concentrations of PAHs, and immune activation (adjuvant effect) at lower dose described by others (Burchiel \& Luster 2001). Given the likely chronic exposure of dolphins to PAHs and other petroleum compounds following the DWH oil spill, and 
the findings of dolphins with primary bacterial pneumonia, the present study aimed to evaluate potential changes in immune functions in bottlenose dolphins inhabiting the DHW oil spill footprint over the first 3 yr following the oil spill.

\section{MATERIALS AND METHODS}

\begin{abstract}
Animals
Bottlenose dolphins were captured, sampled, and released as part of health assessment programs (which included the immunological data presented here), as previously described in detail elsewhere (Wells et al. 2004, Schwacke et al. 2014). Sampling was conducted at 3 GoM sites following the DWH oil spill: BB, Louisiana, an area that received prolonged and heavy oiling (Michel et al. 2013), sampled in 2011, 2013, and 2014; Mississippi Sound (MS), Mississippi, an area relatively less heavily oiled, sampled in 2013; and SB, Florida, an area where no oil was observed following the DWH spill, sampled in 2011, 2012, 2013, and 2014. The well-studied SB population of resident bottlenose dolphins was used as reference in this study (Wells et al. 2004). Mice were used as quality control for functional assays. All procedures were performed under appropriate permits and IACUC approval as detailed in the Supplement at www.int-res.com/articles/suppl/n033p291 _supp.pdf.
\end{abstract}

\section{Blood sampling and immune functions}

Dolphin blood was collected into BD Vacutainer® tubes as part of the physical examinations, kept cool and shipped overnight for functional immunological assays, as routinely performed in previous health assessments (Schwacke et al. 2010, 2012). In addition, serum was collected and immediately frozen prior to shipping on dry ice for cytokine analysis. Cell isolation and details of the immune function tests performed, quality control measures and statistical approaches are described in the Supplement.

\section{RESULTS}

\section{Functional immune assays}

Results for mitogen-induced lymphocyte proliferation are presented in Fig. 1. All 3 mitogens stimulated lymphocyte proliferation in a dose-dependent fashion. When results were expressed as optical density (OD), there was a consistent and significant increase in $\mathrm{T}$ lymphocyte proliferation, in reponse to both concanavalin A (Con A) and phytohemagglutinin (PHA), in BB 2011 dolphins compared to SB, at both sub-optimal and optimal concentrations of mitogens. However, the increase was consistently more marked at sub-optimal concentrations of mitogens (55\% for sub-optimal vs. $44 \%$ for optimal concentrations of Con A, and $164 \%$ for sub-optimal vs. $65 \%$ for optimal concentrations of PHA). The T cell proliferation following stimulation with sub-optimal concentrations of PHA was also significantly higher in the 2013 BB dolphins compared to SB, but to a lesser extent (96\% increase) than in 2011 BB dolphins (164\% increase). The $\mathrm{T}$ cell proliferation following stimulation with sub-optimal concentrations of PHA in 2014 BB and 2014 MS was not significantly different from SB.

A significant increase in B cell proliferation was also observed in BB compared to SB. Sub-optimal stimulation significantly increased B cell proliferation in 2011 (135\% increase), 2013 (125\%) and 2014 $(61 \%)$, while optimal stimulation increased B cell proliferation only in 2011 (83\%) and 2013 (136\%). As with T cells, changes were generally (2011 and 2014, but not 2013) slightly more marked upon sub-optimal lipopolysaccharide (LPS) stimulation than with optimal LPS stimulation. In the absence of mitogens, proliferation was significantly higher in BB (2011, 2013 and 2014) than in SB. No significant effects were observed in MS compared to the SB.

When results were expressed as stimulation index (SI), patterns were generally similar but the variability was greater (as it takes into account both the variability of the mitogen-stimulated cells and that of the unstimulated control), and results were statistically significant only for sub-optimal stimulation with PHA.

The results for $\mathrm{T}$ cell proliferation in SB were robust enough $(\mathrm{n}>40)$ to allow for the generation of reference intervals (RIs). Sample sizes used for evaluations of sub-optimal and optimal levels of ConA and PHA (hereafter SubConA, OptConA, SubPHA, and OptPHA) differed due to laboratory quality control measures, but ranged between 41 and 48 independent observations (Table 1). No outliers were detected for any parameter (Table 1), values did not significantly differ by year or between sexes, and results were not significantly correlated with age. Therefore, RIs calculated for each parameter were not partitioned by any demographic variables (Table 2). 

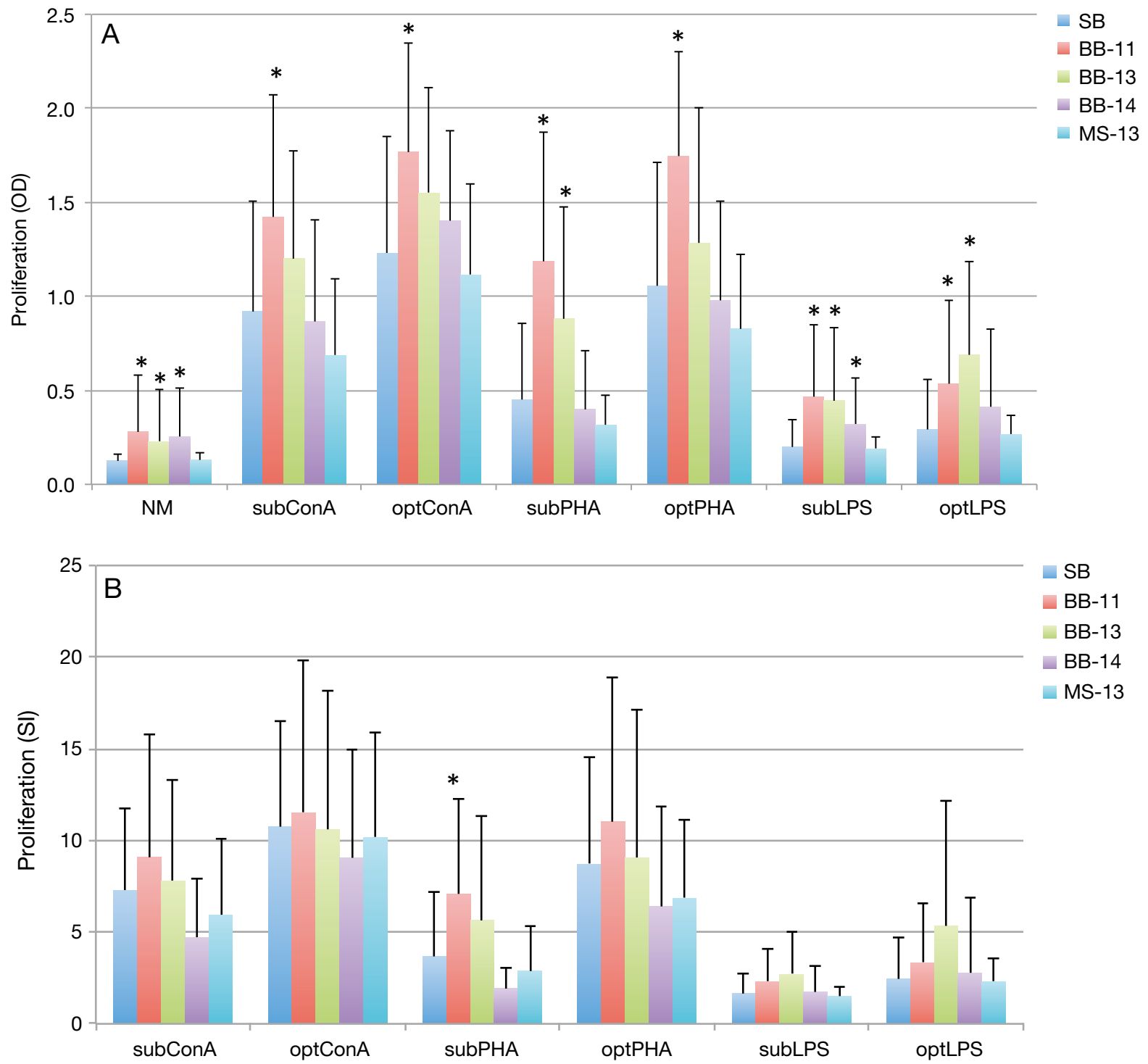

Fig. 1. Lymphocyte proliferation in blood of bottlenose dolphins exposed to varying levels of oiling following the DWH oil spill upon stimulation with optimal (opt) and sub-optimal (sub) concentrations of mitogens, compared to no mitogen stimulation (NM), expressed as (A) optical density (OD) and (B) stimulation index (SI). Samples were obtained from Sarasato Bay (SB), FL, in 2011-2014 ( $\mathrm{n}=60$ dolphins), Barataria Bay (BB), LA, in $2011(\mathrm{n}=29), 2013$ ( $\mathrm{n}=31$ ), and 2014 ( $\mathrm{n}=32$ ) and in Mississippi Sound (MS), MS, in 2013 ( $\mathrm{n}=20$ ). Results are means, and error bars represent standard deviation. ${ }^{*}$ Results significantly different from SB $(p<0.05)$

$\mathrm{T}$ cell proliferation (OD) values from dolphins sampled in BB and MS were compared to threshold values for the $95^{\text {th }}$ percentile RI to identify cases for each parameter (Table 3). For all parameters, the prevalence of cases among dolphins sampled in BB during 2011 was significantly greater than expected, with most cases above the RI threshold (Table 3). In contrast, a significantly high prevalence of
Table 1. Summary statistics for optical density data used to construct $95^{\text {th }}$ percentile reference intervals for $\mathrm{T}$ cell proliferation in response to exposure to sub-optimal (sub) and optimal (opt) levels of the mitogens ConA and PHA (SubConA, OptConA, SubPHA, and OptPHA) in blood samples taken from free-ranging bottlenose dolphins sampled in Sarasota Bay, FL, in 2011-2014

\begin{tabular}{|lcccccccc|}
\hline Parameter & N & Male & Female & Mean & SD & Median & Range & Outliers \\
\hline SubConA & 47 & 24 & 23 & 0.97 & 0.60 & 0.96 & $0.09-2.21$ & 0 \\
OptConA & 48 & 24 & 24 & 1.29 & 0.61 & 1.30 & $0.09-2.34$ & 0 \\
SubPHA & 41 & 20 & 21 & 0.47 & 0.42 & 0.26 & $0.08-1.64$ & 0 \\
OptPHA & 44 & 23 & 21 & 1.05 & 0.67 & 1.06 & $0.02-2.23$ & 0 \\
\hline
\end{tabular}


Table 2. $95^{\text {th }}$ percentile reference intervals (and respective $90 \%$ confidence intervals) for optical density measures of $\mathrm{T}$ cell function in response to exposure to mitogens (for parameters, see Table 1 legend) in blood samples taken from free-ranging bottlenose dolphins in Sarasota Bay, FL, in 2011-2014

\begin{tabular}{|lccc|}
\hline Parameter & $\mathrm{N}$ & $\begin{array}{c}\text { Lower } 95^{\text {th }} \\
(90 \% \mathrm{CI})\end{array}$ & $\begin{array}{c}\text { Upper } 95^{\text {th }} \\
(90 \% \mathrm{CI})\end{array}$ \\
\hline SubConA & 47 & $0.22(0.09-0.30)$ & $2.17(1.84-2.21)$ \\
OptConA & 48 & $0.28(0.09-0.51)$ & $2.22(2.11-2.34)$ \\
SubPHA & 41 & $0.10(0.08-0.15)$ & $1.52(1.12-1.64)$ \\
OptPHA & 44 & $0.10(0.02-0.22)$ & $2.11(2.05-2.23)$ \\
\hline
\end{tabular}

cases was observed only for SubPHA among 2013 BB dolphins. Similarly, the prevalence of SubConA, OptConA, SubPHA, and OptPHA cases was either 0.00 or not significantly greater than expected for dolphins sampled in MS and BB in 2014, and where cases were detected (e.g. BB 2014 and MS 2013 SubConA, BB 2014 SubPHA), values were below the RI threshold (Table 3).

\section{Cytokines}

IL-4, IL-12, and IFN $\gamma$ were measured using both porcine and human reagents. Average values for IL-4 were 700 -fold higher using the porcine kit, which yielded detectable concentrations in $85 \%$ of the samples tested, while the human kit only detected measurable concentrations in $59 \%$ of the samples tested. On the other hand, the human kit yielded average values 1.5- and 9-fold higher for IL-12 and IFN $\gamma$, respectively; measurable concentrations were obtained in 71 and $48 \%$ of the samples for IL-12 and IFN $\gamma$, respectively, using the human kit, and in 54 and $5 \%$, respectively, using the porcine kit. Thus, reported values herein for IL-4 are based on the porcine kit, whereas values for IL-12 and IFN $\gamma$ are based on the human kit.

Serum cytokines varied considerably between individuals (Fig. 2), as expected for samples from wild populations of outbred animals with different ages and health status. There were no statistically significant differences between locations and times when compared to the SB reference. However, some interesting trends were observed. For example, the Th1 cytokines IL-2, IL-12, and IFN $\gamma$ were approximately 2-, 20-, and 4-fold, respectively, lower in BB 2011 compared to the SB reference, with no such differences observed for BB 2013, BB 2014, or MS. Similarly, the Th2 cytokines IL-5, IL-10, and IL-13 were
Table 3. Counts and prevalence of bottlenose dolphins with $\mathrm{T}$ cell function indices above or below $95^{\text {th }}$ percentile reference intervals in response to exposure to mitogens (for parameters, see Table 1 legend). Data is for dolphins from Barataria Bay (BB), LA, and Mississippi Bay (MS), MS, affected by oiling following the DWH oil spill, compared to reference values from unaffected dolphins in Sarasota Bay, FL (Tables $1 \& 2$ ). ' $n$ ' is sample size and 'cases' are numbers of dolphins with values either above ('high') or below ('low') reference interval thresholds. ' $95 \% \mathrm{CI}^{\prime}$ is the binomial confidence interval for the case prevalence. ${ }^{*}$ Prevalence significantly different than expected $(p<0.05)$

\begin{tabular}{|c|c|c|c|c|c|}
\hline $\begin{array}{l}\text { Parameter } \\
\text { Site }\end{array}$ & Year & $\mathrm{n}$ & $\begin{array}{c}\text { Cases } \\
\text { (low/high) }\end{array}$ & $\begin{array}{l}\text { Preva- } \\
\text { lence }\end{array}$ & $95 \% \mathrm{CI}$ \\
\hline \multicolumn{6}{|l|}{ SubConA } \\
\hline $\mathrm{BB}$ & 2011 & 29 & $7(2 / 5)$ & $0.24^{*}$ & $0.10-0.44$ \\
\hline $\mathrm{BB}$ & 2013 & 31 & $0(0 / 0)$ & 0.00 & $0.00-0.11$ \\
\hline $\mathrm{BB}$ & 2014 & 32 & $1(1 / 0)$ & 0.03 & $0.00-0.16$ \\
\hline MS & 2013 & 20 & $2(2 / 0)$ & 0.10 & $0.01-0.32$ \\
\hline \multicolumn{6}{|l|}{ OptConA } \\
\hline $\mathrm{BB}$ & 2011 & 28 & $7(1 / 6)$ & $0.25^{*}$ & $0.11-0.45$ \\
\hline $\mathrm{BB}$ & 2013 & 31 & $2(0 / 2)$ & 0.06 & $0.01-0.21$ \\
\hline $\mathrm{BB}$ & 2014 & 32 & $0(0 / 0)$ & 0.00 & $0.00-0.11$ \\
\hline MS & 2013 & 16 & $0(0 / 0)$ & 0.00 & $0.00-0.21$ \\
\hline \multicolumn{6}{|l|}{ SubPHA } \\
\hline BB & 2011 & 27 & $9(0 / 9)$ & $0.33^{*}$ & $0.17-0.54$ \\
\hline $\mathrm{BB}$ & 2013 & 31 & $5(0 / 5)$ & $0.16^{*}$ & $0.05-0.34$ \\
\hline $\mathrm{BB}$ & 2014 & 32 & $2(2 / 0)$ & 0.06 & $0.01-0.21$ \\
\hline MS & 2013 & 20 & $0(0 / 0)$ & 0.00 & $0.00-0.17$ \\
\hline \multicolumn{6}{|l|}{ OptPHA } \\
\hline $\mathrm{BB}$ & 2011 & 24 & $6(0 / 6)$ & $0.25^{*}$ & $0.10-0.47$ \\
\hline $\mathrm{BB}$ & 2013 & 28 & $2(0 / 2)$ & 0.07 & $0.01-0.24$ \\
\hline $\mathrm{BB}$ & 2014 & 31 & $0(0 / 0)$ & 0.00 & $0.00-0.11$ \\
\hline MS & 2013 & 18 & $0(0 / 0)$ & 0.00 & $0.00-0.19$ \\
\hline
\end{tabular}

approximately 2-, 50-, and 10-fold, respectively, lower in BB 2011 compared to the SB reference, with no comparable differences observed for BB 2013, BB 2014, and MS. IL-4 was 3-fold higher in BB 2011 compared to SB, with no such differences in BB 2013, BB 2014 and MS. The pro-inflammatory cytokines IL-1 $\beta$, TNF $\alpha$ and IL-8 trended differently among locations and time, compared to SB. GM-CSF was 10-fold lower in BB 2011, but was higher in BB 2013, BB 2014, and MS, respectively, compared to SB.

\section{DISCUSSION}

\section{Oil exposure and health effects}

Significant differences were observed in bottlenose dolphin immune functions measured in the northern GoM following the DWH oil spill compared to a reference population of dolphins not exposed to 
Hu IL-2

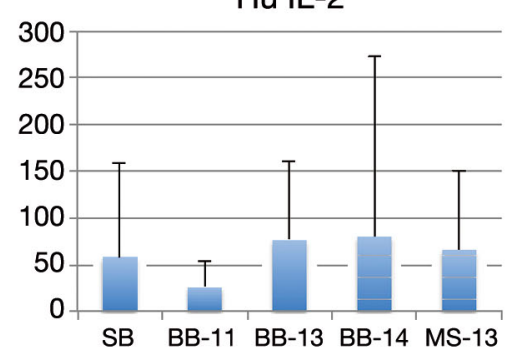

Hu IL-12

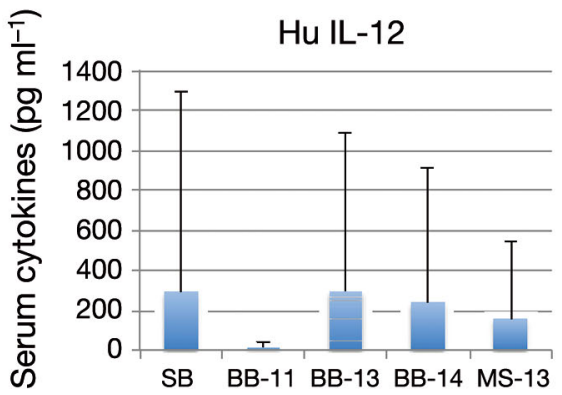

$\mathrm{Hu} I F N g$

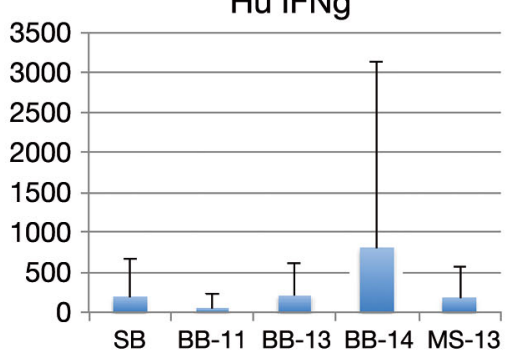

Po IL-4

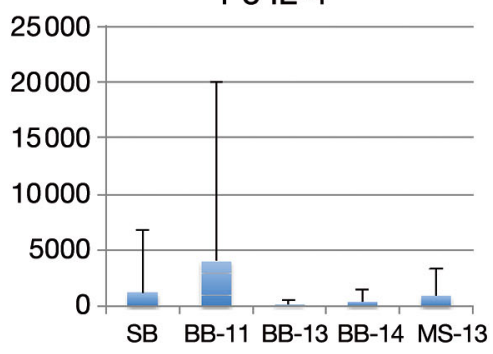

Hu IL-5

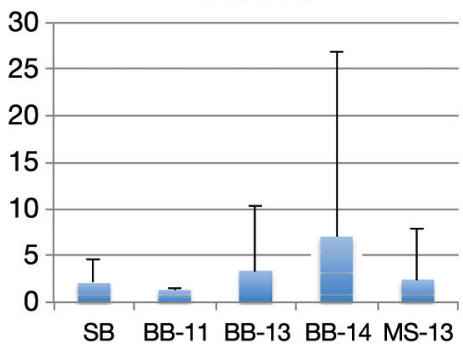

Hu IL-10

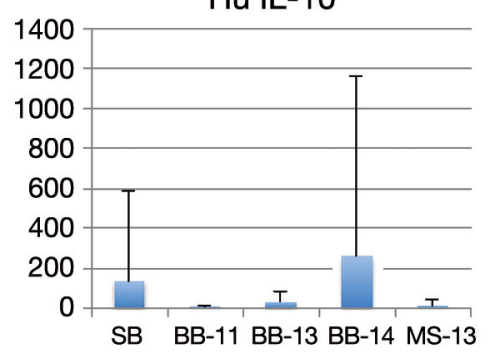

Hu IL-13

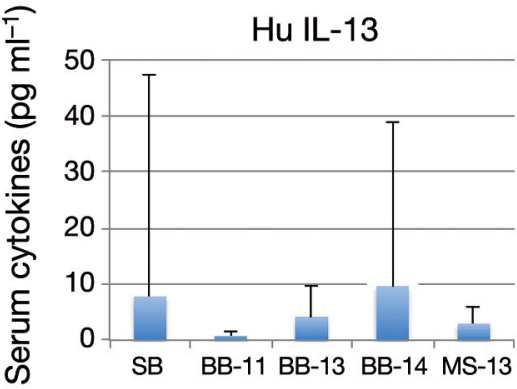

Po IL-1b

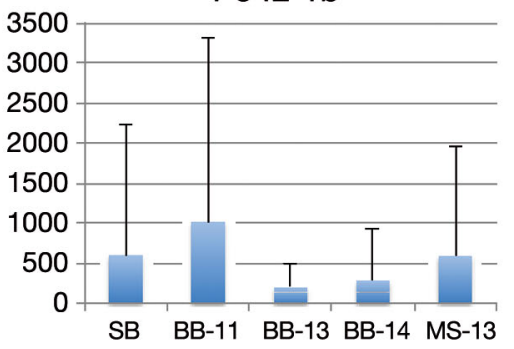

$\mathrm{Hu}$ TNFa

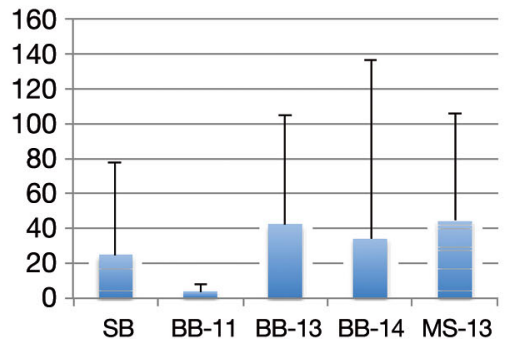

Po IL-8

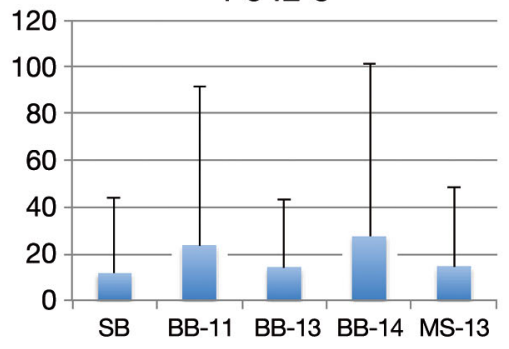

Hu GM-CSF

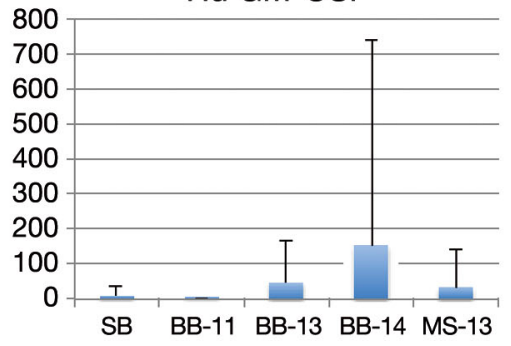

Fig. 2. Serum cytokines $\left(\mathrm{pg} \mathrm{ml}^{-1}\right)$ in blood of bottlenose dolphins following the DWH oil spill, in samples from SB ( $\mathrm{n}=49$ dolphins), BB $2011(\mathrm{n}=32)$, BB $2013(\mathrm{n}=31)$, BB $2014(\mathrm{n}=32)$ and MS $2013(\mathrm{n}=20)$. Measurements were made using the Bio-Plex technology and human (Hu) or porcine (Po) reagents, for Th1 (left panels), Th2 (center panels) and pro-inflammatory (right panels) cytokines. See Fig. 1 legend for abbreviations of study sites and 'Introduction' for abbreviations of cytokines. Results are means, and error bars represent standard deviation

oil, in SB, Florida. While there was no oil exposure directly documented on the animals sampled as part of this study, the DWH oil spill resulted in the contamination of prime marine mammal habitat in the estuarine, nearshore, and offshore waters of the northern GoM, and tens of thousands of marine mammals were exposed to the DWH surface slick, where they likely inhaled, aspirated, ingested, physically contacted, and absorbed oil components (DWH NRDA Trustees 2016). Further, the presence of increased coastal levels of bioavailable PAHs associated with the DWH oil spill, especially near Grand Isle, Louisiana in BB have been confirmed (Allan et al. 2012). It is therefore highly likely that dolphins in BB were exposed to oil as part of the DWH spill, although the exact timing and magnitude of expo- 
sure have not been documented, and it is uncertain how long oil products may have remained in the food chain or in sediments, resulting in potential ongoing dolphin exposure. Further, other studies have documented health effects, including effects on reproduction, respiratory system and adrenal glands, in the same dolphins sampled in 2011, a year following the DWH oil spill (Schwacke et al. 2014, Lane et al. 2015). In addition, some of those health effects were also observed in dead dolphins that stranded in increased numbers following the DWH oil spill (VennWatson et al. 2015). It is also noteworthy that some long-term impacts on marine mammal health have been documented following the Exxon Valdez oil spill, including in sea otters (Monson et al. 2000, Bodkin et al. 2012) and killer whales (Matkin et al. 2008). Few studies have assessed the immunomodulatory effects of oil exposure, and to the authors' knowledge, none have specifically addressed the effects of exposure to petrogenic PAHs. However, there are studies documenting the effects of other PAHs in diverse species, although they represent an imperfect model for the effects of oil exposure. We examine below the nature of the immunological changes observed in view of those described in other species exposed to oil (few studies) or PAHs more broadly, and the potential consequences of those changes.

\section{Oil exposure and $\mathrm{T}$ cells}

The increase in $\mathrm{T}$ cell proliferation was specific in nature and different from those observed in recent bottlenose dolphin health assessments performed using similar methods. Previous health assessments of wild coastal populations of wild bottlenose dolphins using capture-release methods found a negative correlation between $\mathrm{T}$ cell proliferation and exposure to high levels of polychlorinated biphenyls (PCBs) near a superfund site on the coast of Georgia (Schwacke et al. 2012), as well as with exposure to biotoxins and related eosinophilia in St. Joseph Bay, Florida (Schwacke et al. 2010). The effects on $T$ cells, measured as the population average and using the prevalence of animals outside the reference range, also appeared to be site specific (BB but not MS) and/or generally associated with the timing of the spill $(2011>2013>2014)$. Unfortunately, samples from MS were not collected until 2013; therefore, it is impossible to say whether the lack of observed differences for this area was due to the lack of an effect, or whether effects similar to those observed in BB 2011 did occur, but had diminished by 2013. It has been long established that im- munotoxicology studies deal with immune alterations, both stimulatory and suppressive (Burleson \& Dean 1995). Further, extensive studies in laboratory animals suggest that any change, whether an increase or decrease in immune functions, is potentially deleterious (Luster et al. 1992). While exposure to PAHs is generally associated with suppression of mitogen-induced lymphocyte proliferation using in vitro and in vivo models in mammals (Dean et al. 1985, Thurmond et al. 1988, Davila et al. 1996, Karakaya et al. 2004, Zaccaria \& McClure 2013) and fish (Reynaud \& Deschaux 2006), several instances of increased lymphocyte proliferation have been reported in the presence or absence of mitogen stimulation (Tahir \& Secombes 1995, McMurry et al. 1999, Reynaud \& Deschaux 2005, Connelly \& Means 2010) referred to as 'adjuvant effect' (Burchiel \& Luster 2001). In fact, there have been suggestions of immune suppression upon exposure to high concentrations of PAHs, with immune activation at lower doses (Burchiel \& Luster 2001). While it is difficult to quantify the magnitude of PAH exposure in dolphins during the DWH spill compared to controlled experimental studies, the increase in $\mathrm{T}$ cell proliferation in BB 2011 is similar in nature and magnitude to that observed in mink in response to chronic experimental exposure to bunker C fuel oil (Schwartz et al. 2004). Stimulatory effects of PAHs have included an increase in nasal antigen-specific IgE and tilting of the cytokine balance towards a Th2 response in humans (Diaz-Sanchez et al. 1997, Tsien et al. 1997). Also, mice exposed to cyclophosphamide experienced an increase in $\mathrm{T}$ lymphocyte proliferation at lower doses and a decrease in $\mathrm{T}$ cell proliferation at higher doses, which was attributed to the higher sensitivity of regulatory $T$ cells at low dose (Luster et al. 1993). Interestingly, humans with hypoadrenocorticism, a condition also described in BB dolphins in 2011 (Schwacke et al. 2014), showed a downregulation of regulatory $\mathrm{T}$ cells (Treg) (Coles et al. 2005). It is therefore possible that exposure to oil could have modulated the proliferation of $\mathrm{T}$ cells through direct and indirect (adrenal insufficiency) effects on Treg, whose role is to generally dampen the immune response.

\section{Oil exposure and B cells}

The increase in B cell proliferation observed in BB in 2011 and 2013 was site specific and closely associated with the timing of oil exposure (effects in 2011 and 2013; there were some effects in 2014 at suboptimal LPS concentrations, but not at optimal concentrations). It is also specific and different from the 
effects observed in other locations (Schwacke et al. 2010, 2012). For example, 6-mo exposure to diesel exhaust increased the proliferation of mouse splenic B lymphocytes at the lowest dose used $\left(30 \mu \mathrm{g} \mathrm{m}^{-3}\right)$, but not at higher doses (Burchiel et al. 2004). While the proliferation of B lymphocytes was not assessed directly, experimental exposure of mink to bunker $\mathrm{C}$ fuel oil resulted in the expression of an increased density of MHC II on B cells, suggesting B cell activation (Schwartz et al. 2004). Activation of $B$ and $T$ cells was also observed in workers occupationally exposed to PAHs (Biró et al. 2002). Such B cell activation, in the absence of an antigen, could increase their response to a mitogen, as seen in our study.

\section{Oil exposure and Th1/Th2 cytokines}

Previous studies have documented the modulation of cytokines upon exposure to PAHs. Similar to the trend in our study for BB 2011, PAH exposure mostly resulted in down regulation of Th1 cytokines. In vitro IL-2 production in mouse splenocytes was suppressed by dimethylbenz(a)anthracene (DMBA) (Thurmond et al. 1988), and DMBA-induced suppression of CTL was restored with the addition of IL-2, suggesting that DMBA suppressed IL-2 in vivo as well (Dean et al. 1985). Human dendritic cells matured in vitro in the presence of $\mathrm{BaP}$ secreted less IL-12 than unexposed control cells (Laupeze et al. 2002). Similarly, in a mouse allergy model, the broncho-alveolar lavage fluid had suppressed IL-12 upon exposure to PAHs extracted from diesel exhaust particles (Stevens et al. 2009). IL-12 was also reduced following dermal exposure to PAHs in humans (Borska et al. 2008). IFN $\gamma$ was down regulated upon in vitro BaP exposure of human cell lines (Tang et al. 2012) and olive flounder Paralichthys olivaceus head kidney cells (Hur et al. 2013). The mediation of IFN $\gamma$ appeared to be mediated through a calcium-dependent pathway (i.e. nuclear factor of activated $\mathrm{T}$ cells [NFAT]) as it was blocked by ethyleneglycol-bistetraacetic acid (EGTA) (Hur et al. 2013).

The effects of PAH exposure on Th2 cytokines have also been described in other species. For example, human dendritic cells matured in vitro in the presence of $\mathrm{BaP}$ secreted less IL-10 than unexposed control cells (Laupeze et al. 2002). BaP administration in rats (Rattus norvegicus) resulted in a 2.6-fold increase in IL-4 mRNA in the blood (Al-Daghri et al. 2014). BaP and phenanthrene significantly enhanced the production of IL-4 in human basophils upon in vitro exposure (Schober et al. 2007). In a spatial- temporal regression model over multiple time periods, ambient PAH exposure in children was associated with decreased IL-10 and increased IL-4, along with increased IL-13 and IFN $\gamma$ (Hew et al. 2015). Overall, while not statistically significant, the trend was towards lower Th1 and Th2 cytokines except for higher levels of IL-4 in BB 2011, likely resulting in a tilt of the balance towards Th2 given the dominant role of IL- 4 in the Th1/Th2 regulation, which would be compatible with the outcome of several experimental studies. Further, depletion studies in mice have demonstrated the ability of Treg to influence the Th1/Th2 cytokine balance (Xiong et al. 2015), offering the possibility of an indirect pathway.

\section{Oil exposure and pro-inflammatory cytokines}

Pro-inflammatory cytokines did not all vary similarly in our study, with trends towards higher Il-1 $\beta$ and IL-8 in BB 2011, as was the case in human macrophage exposed to $\mathrm{BaP}$ in vitro (Sparfel et al. 2010), and in olive flounders exposed to $\mathrm{BaP}$ in vivo and in vitro (Hur et al. 2013). In another report, human macrophage exposure to $\mathrm{BaP}$ enhanced the production of IL-8 in a dose-dependent manner through the AhR pathway (Podechard 2008). TNF $\alpha$ was 7 -fold lower in BB 2011 as compared to the SB reference site. $\mathrm{BaP}$ exposure of human monocytes in vitro reduced the production of $\mathrm{TNF} \alpha$ approximately 9 fold (van Grevenynghe et al. 2003). However, this is different from most studies where TNF $\alpha$ is increased upon exposure to $\mathrm{BaP}$, including in human models (Lecureur et al. 2005, Sparfel et al. 2010) and in olive flounder upon in vivo and in vitro exposures (Hur et al. 2013). It is possible that differences between species are associated with differences in pathway/ receptors, since BaP-induced modulation of TNF $\alpha$ was reported to occur through a AhR-independent, extracellular signal-regulated kinases (ERK)-related pathway in human macrophages (Lecureur et al. 2005), while it was reported to occur via the AHR pathway in olive flounder, as it was blocked by ANF (Hur et al. 2013).

\section{Oil exposure, immune functions and reproduction}

The bottlenose dolphin unusual mortality event in the northern GoM was associated with significant increases in perinatal mortality (Venn-Watson et al. 2015). Maintenance of pregnancy requires a complex series of immunological events leading to local (intra- 
uterine) tolerance of the embryo/fetus by the mother's immune system, rather than immunological rejection. In humans, the major mechanisms involved in intrauterine tolerance include the expression of the non-classical human major histocompatibility (MHC) class Ib and its inhibitory effects on uterine natural killer (NK) cells, as well as the IL-10 mediated interaction between Treg and specialized tolerogenic dendritic cells (DCs) (Lynge Nilsson et al. 2014). If immune processes in the dolphin are similar to humans, it is plausible that immune tolerance towards the fetus may have been compromised if the ability to produce intrauterine IL-10 was downregulated as appeared to be the case systematically, with serum levels in BB 2011 that were 50-fold lower than in SB. Further, it is possible that immune tolerance may have been compromised if intrauterine Treg cells were downregulated, as described systemically in humans with hypoadrenocorticism (Coles et al. 2005), as evidenced in BB 2011 (Schwacke et al. 2014). Several functional studies have shown that unexplained infertility, miscarriage and pre-clampsia are often associated with deficits in Treg cell numbers and function, while normal pregnancy selectively stimulates the accumulation of maternal Treg cells with fetal specificity (La Rocca et al. 2014). Unfortunately, we do not have data to directly support such potential mechanisms in dolphins from our health assessment data.

\section{Oil exposure, immune functions and perinatal mortalities}

Increased perinatal mortalities in the northern GoM unusual mortality event were associated with a high prevalence of in utero deaths, fetal distress, and non-lungworm associated pneumonia in the fetus compared to reference stranded dolphin perinatal populations. In Mississippi and Alabama, stranded perinates also had a high prevalence of Brucella infections involving multiple genetic subtypes across the region (Colegrove et al. 2016). The importance of the Th1/Th2 paradigm for the control of Brucella infection was demonstrated almost 2 decades ago in mice, where the predominance of the Th2 cytokines IL-4 and IL-10 in the BALB/C mice was associated with increased susceptibility to Brucella, whereas the predominance of the Th1 cytokine IFN $\gamma$ in the C57BL/10 mice was associated with increased resistance to Brucella (Fernandes et al. 1996, Baldwin \& Parent 2002). Further, mouse studies with IFN regulation confirmed the importance of IFN $\gamma$ and IL-12 for resistance to Brucella infection (Ko et al. 2002), especially in the first weeks after infection when relative resistance to brucellosis correlated with increased production of IFN $\gamma$ by CD4 T cells (Baldwin \& Parent 2002). Mouse macrophages activated with IFN $\gamma$ were shown to have enhanced brucellacidal and brucellastatic activities (Jiang et al. 1993). Additional knockout studies in mice demonstrated that IFN $\gamma$ appears to be more important than IL-12 for controlling the magnitude of Brucella infections (Brandao et al. 2012). Susceptibility of MyD88 KO mice to Brucella abortus was due to impaired dendritic cell maturation and lack of IL-12 synthesis (Macedo et al. 2008). The administration of recombinant IL-12 to susceptible BALB/c mice ameliorated the IFN $\gamma$ hiatus associated with susceptibility, resulting in a 1000-fold reduction in colony-forming units (CFU) during primary Brucella infection and increased survival following secondary challenge (Sathiyaseelan et al. 2006). B. abortus vaccine strain 19 replicated much better in IL-6-/- than in IL-6+/+ mice (Pizarro-Cerdá et al. 1999). Altogether, those studies confirm the detrimental effects of the Th2 cytokines IL-4, IL-6 and IL-10, and the positive effects of the Th1 cytokines IFN $\gamma$ and IL-12 in resistance to Brucella infection in mice. Similarly, monocyte-derived macrophages from resistant cows had the ability to mount a Th1 immune response against $B$. abortus infection, which was impaired in cells from susceptible animals (Rossetti et al. 2011). It is plausible that a Th1 reduction and tilt towards a Th2 response in BB 2011, if biologically significant despite not being statistically significant, would increase the susceptibility of those dolphins to Brucella infection or other intracellular pathogens. Increased susceptibility to bacterial challenges, including intra-cellular Mycobacterium marinum, upon PAH exposure was specifically confirmed in several studies in fish (Bravo et al. 2011, Prosser et al. 2011).

\section{Potential causes and consequences of changes in immune functions}

A broad and comprehensive hallmark study in laboratory animals concluded that there was a good correlation between changes in immune function tests and altered host resistance (Luster et al. 1993). In that study, there were no instances of altered host resistance without altered immune test results. However, there were instances of immune changes without detectable changes in host resistance, mostly attributable to the specificity of the immune function 
changes (mechanistically relevant) in relation to the challenge, i.e. challenges with a pathogen that was not relevant to the immune functions affected. The same authors suggested that, considering the presence of background levels of infectious diseases in natural populations, it is possible that any change in immune functions could translate to changes in host resistance if the population exposed is large enough (Luster et al. 1993). In other words, if immune functions of a natural population are affected, it is highly likely that there will be a pathogen somewhere in the environment of the population that will be relevant to the immune functions affected. These authors suggested that the relationship between immune disfunctions and infectious diseases is linear rather than involving a threshold (Luster et al. 1993).

A broad diversity of chemicals can alter immune functions, and the changes observed here are compatible with, but not necessarily specific to, exposure to oil. The effects of PCBs and other persistent organic pollutants (POPs) on immune functions have been widely described, and our group has previously demonstrated immune alterations associated with PCB exposure in bottlenose dolphins near a superfund site on the coast of Georgia (Schwacke et al. 2012). However, POP concentrations in Barataria Bay bottlenose dolphins were in the lower half of the range compared to previously reported concentrations from other southeastern US sites, suggesting that POPs were likely not a primary contributor to the poor health conditions and increased mortality observed in northern GoM dolphins following the DWH oil spill (Balmer et al. 2015). Several pathogens can be associated with modulation of immune functions, including morbilliviruses. A thorough investigation of the northern GoM unusual mortality event associated in time and space with the DWH oil spill concluded that brucellosis and morbillivirus infections were detected in 7 and $11 \%$ of unusual mortality event dolphins, respectively, and biotoxin levels were low or below the detection limit, indicating that these were not primary causes of the current unusual mortality event (Venn-Watson et al. 2015). Further, it was unlikely that other pathogens would have been causing widespread diseases, based on the results of histopathological examinations (Venn-Watson et al. 2015). Stress exposure has also long been associated with immune system modulation via the secretion of corticosteroids. However, the dolphins sampled in this study suffered from hypoadrenocorticism, with low serum cortisol and aldosterone (Schwacke et al. 2014). It is therefore unlikely that exposure to POPs, the most common pathogens associated with dolphin morbidity and mortality, biotoxins, or stress would have been responsible for the changes in immune functions reported here. It is possible that other emerging or legacy contaminants or pathogens not measured as part of this investigation may be associated with the immune changes observed. However, this is unlikely compared to the weight of evidence for the DWH oil spill and its association with other health effects.

It is possible that changes in $\mathrm{T}$ cell functions, and possibly the cytokine balance (if the changes observed were to be biologically significant, despite the fact that they are not statistically significant, given the broad variability in a diverse population of wild and outbred animals), would have resulted in increased susceptibility to intra-cellular pathogens, while changes in B cell functions would have resulted in increased susceptibility to extracellular pathogens such as bacteria that could have been involved in the high incidence of primary bacterial pneumonia observed in the northern GoM unusual mortality event. A conceptual model is presented in Fig. 3 to summarize the potential relationships be-

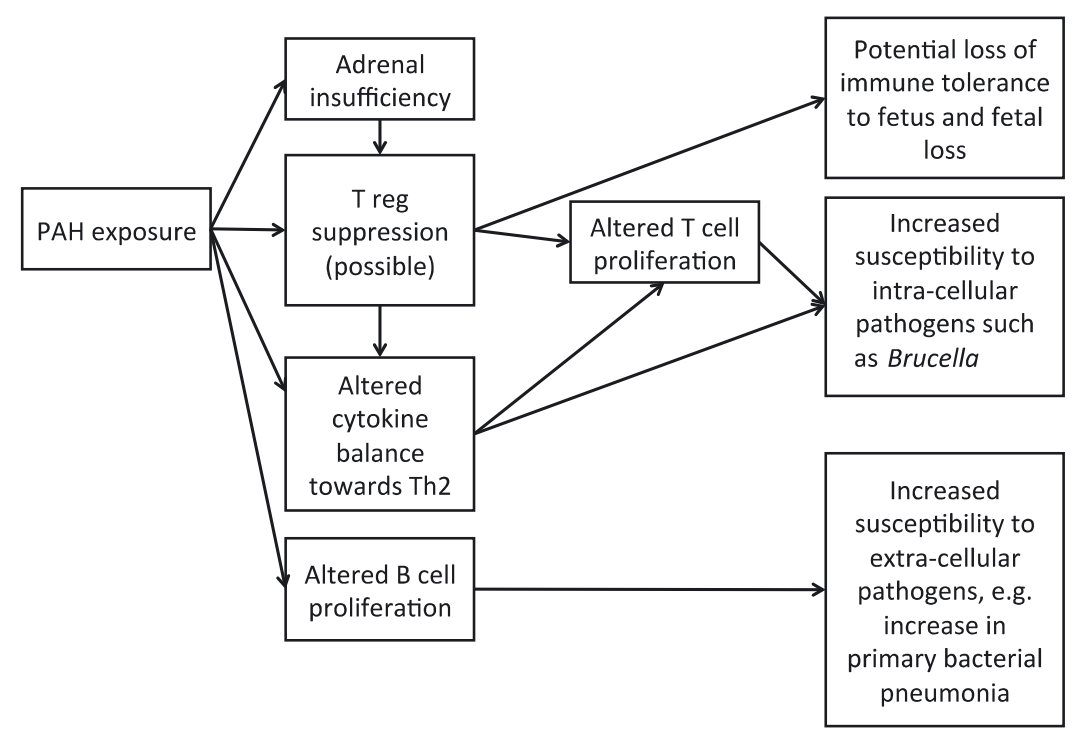

Fig. 3. Conceptual model summarizing the potential relationships between the changes in immune function and the health effects observed in live and dead dolphins following the DWH oil spill. The conceptual model is based on observations, and links supported by relevant literature. PAH: polycyclic aromatic hydrocarbon; Th2: T helper 2 lymphocytes 
tween the changes in immune function and the health effects observed in live and dead dolphins associated with the DWH oil spill.

While our results demonstrate associations between dolphins living in DWH-contaminated waters and changes in $\mathrm{T}$ and $\mathrm{B}$ lymphocyte proliferation, as well as trends towards a Th2-biased cytokine balance, they do not confirm a cause and effect relationship. However, the alterations in $\mathrm{T}$ and $\mathrm{B}$ lymphocyte proliferation were comparable in nature and magnitude to those observed in mink with chronic experimental exposure to oil (Schwartz et al. 2004), and compatible with those observed in humans exposed to PAHs (Biró et al. 2002). The altered $\mathrm{T}$ and $\mathrm{B}$ lymphocyte proliferation was consistent in time and space with exposure to oil from DWH as it occurred mostly in BB 2011, the area and time when sampled dolphins would be most affected by oil, and some of the changes observed were less severe or subsiding in subsequent years. The increase in $\mathrm{T}$ and $\mathrm{B}$ lymphocyte proliferation was specific to $\mathrm{BB}$, and different from the negative correlation between $\mathrm{T}$ cell proliferation exposure to PCBs (Schwacke et al. 2010) or biotoxins (Schwacke et al. 2012) observed in wild dolphin populations. Further, the altered $\mathrm{T}$ and $\mathrm{B}$ lymphocyte proliferation observed, and the trends towards a Th2-biased cytokine balance, if biologically significant, would be expected to increase susceptibility to infectious disease, and are consistent with the bottlenose dolphin unusual mortality event investigation results that found increased respiratory disease, often associated with bacteria, but did not identify a specific single pathogen. The increase in perinatal mortality and associated Brucella infection, an intra-cellular bacterial infection for which $\mathrm{T}$ cells and a Th1 predominant response are particularly important, could be at least in part explained with the $\mathrm{T}$ cell changes observed here. The increase in frequency of primary bacterial pneumonia could be at least in part explained by the B cell changes observed here. The sum of the lines of evidence above, along with the lack of evidence for alternative causes, suggests that the immune changes reported here could be associated with exposure to oil from the DWH spill.

Disclaimer. This work was part of the DWH Natural Resource Damage Assessment (NRDA) being conducted cooperatively among NOAA, other federal and state Trustees, and BP plc. The findings and conclusions in this paper are those of the authors and do not necessarily represent the view of NOAA or of any other natural resource Trustee for the BP/DWH NRDA.
Acknowledgements. The authors wish to thank the numerous researchers, staff members and volunteers who provided support for the dolphin health assessment field work.

\section{LITERATURE CITED}

Al-Daghri NM, Abd-Alrahman S, Draz H, Alkharfy K, Mohammed AK, Clerici MS, Alokail MS (2014) Increased IL4 mRNA expression and poly-aromatic hydrocarbon concentrations from children with asthma. BMC Pediatr $14: 17$

Allan SE, Smith BW, Anderson KA (2012) Impact of the Deepwater Horizon oil spill on bioavailable polycyclic aromatic hydrocarbons in the Gulf of Mexico coastal waters. Environ Sci Technol 46:2033-2039

*Baldwin CL, Parent M (2002) Fundamentals of host immune response against Brucella abortus: what the mouse model has revealed about control of infection. Vet Microbiol 90:367-382

* Balmer BC, Ylitalo GM, McGeorge LE, Baugh KA and others (2015) Persistent organic pollutants (POPs) in blubber of common bottlenose dolphins (Tursiops truncatus) along the northern Gulf of Mexico coast, USA. Sci Total Environ 527-528:306-312

* Biró A, Pallinger E, Major J, Jakab MG, Klupp T, Falus A, Tompa A (2002) Lymphocyte phenotype analysis and chromosome aberration frequency of workers occupationally exposed to styrene, benzene, polycyclic aromatic hydrocarbons or mixed solvents. Immunol Lett 81: 133-140

* Bodkin JL, Ballachey BE, Coletti HA, Esslinger GG and others (2012) Long-term effects of the 'Exxon Valdez' oil spill: sea otter foraging in the intertidal as a pathway of exposure to lingering oil. Mar Ecol Prog Ser 447:273-287

* Borska L, Andrys C, Krejsek J, Hamakova K, Kremlacek J, Ettler K, Fiala Z (2008) Serum levels of the pro-inflammatory cytokine interleukin-12 and the anti-inflammatory cytokine interleukin-10 in patients with psoriasis treated by the Goeckerman regimen. Int J Dermatol 47:800-805

*Bandao AP, Oliveira FS, Carvalho NB, Vieira LQ, Azevedo V, Macedo GC, Oliveira SC (2012) Host susceptibility to Brucella abortus infection is more pronounced in IFN-gamma knockout than IL-12/beta2-microglobulin double-deficient mice. Clin Dev Immunol 2012:589494

* Bravo CF, Curtis LR, Myers MS, Meador JP and others (2011) Biomarker responses and disease susceptibility in juvenile rainbow trout Oncorhynchus mykiss fed a high molecular weight PAH mixture. Environ Toxicol Chem 30:704-714

* Burchiel SW, Luster MI (2001) Signaling by environmental polycyclic aromatic hydrocarbons in human lymphocytes. Clin Immunol 98:2-10

*Burchiel SW, Lauer FT, McDonald JD, Reed MD (2004) Systemic immunotoxicity in AJ mice following 6-month whole body inhalation exposure to diesel exhaust. Toxicol Appl Pharmacol 196:337-345

Burleson GR, Dean JH (1995) Immunotoxicology: past, present, and future. In: Burleson GR, Dean JH, Munson_AE (eds) Methods in immunotoxicology. Wiley-Liss, New York, NY, p 3-10

Colegrove KM, Venn-Watson S, Litz J, Kinsel MJ and others (2016) Fetal distress and in utero pneumonia in perinatal dolphins during the Northern Gulf of Mexico unusual mortality event. Dis Aquat Org 119:1-16 
Coles AJ, Thompson S, Cox AL, Curran S, Gurnell EM, Chatterjee VK (2005) Dehydroepiandrosterone replacement in patients with Addison's disease has a bimodal effect on regulatory (CD4+CD25hi and CD4+FoxP3+) T cells. Eur J Immunol 35:3694-3703

Connelly H, Means JC (2010) Immunomodulatory effects of dietary exposure to selected polycyclic aromatic hydrocarbons in the bluegill (Lepomis macrochirus). Int J Toxicol 29:532-545

Davila DR, Davis DP, Campbell K, Cambier JC, Zigmond LA, Burchiel SW (1995) Role of alterations in $\mathrm{Ca}^{2+}$-associated signaling pathways in the immunotoxicity of polycyclic aromatic hydrocarbons. J Toxicol Environ Health 45:101-126

Davila DR, Romero DL, Burchiel SW (1996) Human T cells are highly sensitive to suppression of mitogenesis by polycyclic aromatic hydrocarbons and this effect is differentially reversed by alpha-naphthoflavone. Toxicol Appl Pharmacol 139:333-341

De Guise S, Bernier J, Dufresne MM, Martineau D, Beland P, Fournier M (1996) Immune functions in beluga whales (Delphinapterus leucas): evaluation of mitogen-induced blastic transformation of lymphocytes from peripheral blood, spleen and thymus. Vet Immunol Immunopathol 50:117-126

Dean JH, Ward EC, Murray MJ, Lauer LD, House RV (1985) Mechanisms of dimethylbenzanthracene-induced immunotoxicity. Clin Physiol Biochem 3:98-110

* Diaz-Sanchez D, Tsien A, Fleming J, Saxon A (1997) Combined diesel exhaust particulate and ragweed allergen challenge markedly enhances human in vivo nasal ragweed-specific IgE and skews cytokine production to a T helper cell 2-type pattern. J Immunol 158:2406-2413

DWH NRDA (Deepwater Horizon Natural Resource Damage Assessment) Trustees (2016) Deepwater Horizon oil spill: final programmatic damage assessment and restoration plan and final programmatic environmental impact statement. www.gulfspillrestoration.noaa.gov/restorationplanning/gulf-plan (Accessed on 13 February 2017)

Fernandes DM, Jiang X, Jung JH, Baldwin CL (1996) Comparison of $\mathrm{T}$ cell cytokines in resistant and susceptible mice infected with virulent Brucella abortus strain 2308. FEMS Immunol Med Microbiol 16:193-203

Gubbay S, Earll R (2000). Review of literature on the effects of oil spills on cetaceans. Scottish Natural Heritage, Edinburgh

Hew KM, Walker AI, Kohli A, Garcia M and others (2015) Childhood exposure to ambient polycyclic aromatic hydrocarbons is linked to epigenetic modifications and impaired systemic immunity in T cells. Clin Exp Allergy 45:238-248

*Hur D, Jeon JK, Hong S (2013) Analysis of immune gene expression modulated by benzo[a]pyrene in head kidney of olive flounder (Paralichthys olivaceus). Comp Biochem Physiol B Biochem Mol Biol 165:49-57

Jiang X, Leonard B, Benson R, Baldwin CL (1993) Macrophage control of Brucella abortus: role of reactive oxygen intermediates and nitric oxide. Cell Immunol 151: 309-319

Karakaya A, Ates I, Yucesoy B (2004) Effects of occupational polycyclic aromatic hydrocarbon exposure on T-lymphocyte functions and natural killer cell activity in asphalt and coke oven workers. Hum Exp Toxicol 23:317-322

Ko J, Gendron-Fitzpatrick A, Splitter GA (2002) Susceptibility of IFN regulatory factor-1 and IFN consensus se- quence binding protein-deficient mice to brucellosis. J Immunol 168:2433-2440

Kuby J (1997) Immunology. W.H. Freeman, New York, NY

* La Rocca C, Carbone F, Longobardi S, Matarese G (2014) The immunology of pregnancy: regulatory $\mathrm{T}$ cells control maternal immune tolerance toward the fetus. Immunol Lett 162:41-48

Lane SM, Smith CR, Mitchell J, Balmer BC and others (2015) Reproductive outcome and survival of common bottlenose dolphins sampled in Barataria Bay, Louisiana, USA, following the Deepwater Horizon oil spill. Proc R Soc B 282: 20151944

*aupeze B, Amiot L, Sparfel L, Le Ferrec E, Fauchet R, Fardel O (2002) Polycyclic aromatic hydrocarbons affect functional differentiation and maturation of human monocyte-derived dendritic cells. J Immunol 168: 2652-2658

* Lecureur V, Ferrec EL, N'Diaye M, Vee ML, Gardyn C, Gilot D, Fardel O (2005) ERK-dependent induction of TNF $\alpha$ expression by the environmental contaminant benzo(a) pyrene in primary human macrophages. FEBS Lett 579:1904-1910

* Luster MI, Portier C, Pait DG, White KL Jr, Gennings C, Munson AE, Rosenthal GJ (1992) Risk assessment in immunotoxicology. I. Sensitivity and predictability of immune tests. Fundam Appl Toxicol 18:200-210

* Luster MI, Portier C, Pait DG, Rosenthal GJ and others (1993) Risk assessment in immunotoxicology. II. Relationships between immune and host resistance tests. Fundam Appl Toxicol 21:71-82

Lynge Nilsson L, Djurisic S, Hviid TV (2014) Controlling the immunological crosstalk during conception and pregnancy: HLA-G in reproduction. Front Immunol 5:198

Macedo GC, Magnani DM, Carvalho NB, Bruna-Romero O, Gazzinelli RT, Oliveira SC (2008) Central role of MyD88dependent dendritic cell maturation and proinflammatory cytokine production to control Brucella abortus infection. J Immunol 180:1080-1087

*Matkin CO, Saulitis EL, Ellis GM, Olesiuk P, Rice SD (2008) Ongoing population-level impacts on killer whales Orcinus orca following the 'Exxon Valdez' oil spill in Prince William Sound, Alaska. Mar Ecol Prog Ser 356:269-281

McMurry ST, Lochmiller RL, McBee K, Qualls CW Jr (1999) Indicators of immunotoxicity in populations of cotton rats (Sigmodon hispidus) inhabiting an abandoned oil refinery. Ecotoxicol Environ Saf 42:223-235

Michel J, Owens EH, Zengel S, Graham A and others (2013) Extent and degree of shoreline oiling: Deepwater Horizon oil spill, Gulf of Mexico, USA. PLOS ONE 8:e65087

* Monson DH, Doak DF, Ballachey BE, Johnson A, Bodkin JL (2000) Long-term impacts of the Exxon Valdez oil spill on sea otters, assessed through age-dependent mortality patterns. Proc Natl Acad Sci USA 97:6562-6567

* Pizarro-Cerdá J, Desjardins M, Moreno E, Akira S, Gorvel JP (1999) Modulation of endocytosis in nuclear factor IL6(-/-) macrophages is responsible for a high susceptibility to intracellular bacterial infection. J Immunol 162:3519-3526

* Podechard N, Lecureur V, Le Ferrec E, Guenon I and others (2008) Interleukin-8 induction by the environmental contaminant benzo(a)pyrene is aryl hydrocarbon receptordependent and leads to lung inflammation. Toxicol Lett 177:130-137

* Prosser CM, Unger MA, Vogelbein WK (2011) Multistressor interactions in the zebrafish (Danio rerio): concurrent 
phenanthrene exposure and Mycobacterium marinum infection. Aquat Toxicol 102:177-185

Reynaud S, Deschaux P (2005) The effects of 3-methylcholanthrene on lymphocyte proliferation in the common carp (Cyprinus carpio L.). Toxicology 211:156-164

Reynaud S, Deschaux P (2006) The effects of polycyclic aromatic hydrocarbons on the immune system of fish: a review. Aquat Toxicol 77:229-238

Rossetti CA, Galindo CL, Everts RE, Lewin HA, Garner HR, Adams LG (2011) Comparative analysis of the early transcriptome of Brucella abortus - infected monocytederived macrophages from cattle naturally resistant or susceptible to brucellosis. Res Vet Sci 91:40-51

Sathiyaseelan J, Goenka R, Parent M, Benson RM and others (2006) Treatment of Brucella-susceptible mice with IL-12 increases primary and secondary immunity. Cell Immunol 243:1-9

Schober W, Lubitz S, Belloni B, Gebauer G and others (2007) Environmental polycyclic aromatic hydrocarbons (PAHs) enhance allergic inflammation by acting on human basophils. Inhal Toxicol 19(Suppl 1):151-156

Schwacke LH, Twiner MJ, De Guise S, Balmer BC and others (2010) Eosinophilia and biotoxin exposure in bottlenose dolphins (Tursiops truncatus) from a coastal area impacted by repeated mortality events. Environ Res 110: 548-555

Schwacke LH, Zolman ES, Balmer BC, De Guise S and others (2012) Anaemia, hypothyroidism and immune suppression associated with polychlorinated biphenyl exposure in bottlenose dolphins (Tursiops truncatus). Proc R Soc B 279:48-57

Schwacke LH, Smith CR, Townsend FI, Wells RS and others (2014) Health of common bottlenose dolphins (Tursiops truncatus) in Barataria Bay, Louisiana, following the Deepwater Horizon oil spill. Environ Sci Technol 48: 93-103

Schwartz JA, Aldridge BM, Stott JL, Mohr FC (2004) Immunophenotypic and functional effects of bunker $\mathrm{C}$ fuel oil on the immune system of American mink (Mustela vison). Vet Immunol Immunopathol 101:179-190

Sparfel L, Pinel-Marie ML, Boize M, Koscielny S, Desmots S, Pery A, Fardel O (2010) Transcriptional signature of human macrophages exposed to the environmental contaminant benzo(a)pyrene. Toxicol Sci 114:247-259

Stevens T, Cho SH, Linak WP, Gilmour MI (2009) Differen-

Editorial responsibility: Karina Acevedo-Whitehouse, Queretaro, Mexico tial potentiation of allergic lung disease in mice exposed to chemically distinct diesel samples. Toxicol Sci 107: 522-534

Tahir A, Secombes CJ (1995) The effects of diesel oil-based drilling mud extracts on immune responses of rainbow trout. Arch Environ Contam Toxicol 29:27-32

* Tang WY, Levin L, Talaska G, Cheung YY and others (2012) Maternal exposure to polycyclic aromatic hydrocarbons and 5'-CpG methylation of interferon- $\gamma$ in cord white blood cells. Environ Health Perspect 120:1195-1200

* Thurmond LM, House RV, Lauer LD, Dean JH (1988) Suppression of splenic lymphocyte function by 7,12 dimethylbenz[a]anthracene (DMBA) in vitro. Toxicol Appl Pharmacol 93:369-377

*Tsien A, Diaz-Sanchez D, Ma J, Saxon A (1997) The organic component of diesel exhaust particles and phenanthrene, a major polyaromatic hydrocarbon constituent, enhances IgE production by IgE-secreting EBV-transformed human B cells in vitro. Toxicol Appl Pharmacol 142:256-263

United States District Court (2014) Oil spill by the oil rig "Deepwater Horizon" in the Gulf of Mexico, on April 20, 2010. www.uscourts.gov/courts/laed/9092014Revised FindingsofFactandConclusionsofLaw.pdf (accessed on 25 April 2017)

* van Grevenynghe J, Rion S, Le Ferrec E, Le Vee M, Amiot L, Fauchet R, Fardel O (2003) Polycyclic aromatic hydrocarbons inhibit differentiation of human monocytes into macrophages. J Immunol 170:2374-2381

Venn-Watson S, Colegrove KM, Litz J, Kinsel M and others (2015) Adrenal gland and lung lesions in Gulf of Mexico common bottlenose dolphins (Tursiops truncatus) found dead following the Deepwater Horizon oil spill. PLOS ONE 10:e0126538

*Wells RS, Rhinehart HL, Hansen LJ, Sweeney JC and others (2004) Bottlenose dolphins as marine ecosystem sentinels: developing a health monitoring system. EcoHealth $1: 246-254$

Xiong S, Guo R, Yang Z, Xu L and others (2015) Treg depletion attenuates irradiation-induced pulmonary fibrosis by reducing fibrocyte accumulation, inducing Th17 response, and shifting IFN- $\gamma$, IL-12/IL-4, IL-5 balance. Immunobiology 220:1284-1291

Zaccaria KJ, McClure PR (2013) Using immunotoxicity information to improve cancer risk assessment for polycyclic aromatic hydrocarbon mixtures. Int J Toxicol 32:236-250

Submitted: June 6, 2016; Accepted: January 29, 2017

Proofs received from author(s): April 26, 2017 